\title{
THE EFFECT OF SEMANTIC MAPPING STRATEGY ON STUDENTS' SPEAKING ACHIEVEMENT IN SMP BUDI MURNI 3
}

\author{
Firdha Sabrina \\ Faculty of English Applied Linguistics \\ State University of Medan \\ sabrinafirdha@gmail.com \\ Fitri Sinurat \\ Faculty of English Applied Linguistics \\ State University of Medan \\ fitrisusi964@yahoo.com
}

\begin{abstract}
This study aims to discover the effect of applying Semantic Mapping Strategy on students' speaking achievement. It will be conducted by using experimental research design. The population of this research is the eight (VIII) grade students of SMP Budi Murni 3. The samples of the research are two classes divided into two groups, experimental and control group which will be chosen by using random sampling technique. Thirty-one students will be taken as the samples. The experimental group will be taught by using Semantic Mapping Strategy, while the control group will be taught by without using Semantic Mapping Strategy. After analyzing the data, it was found that the value of tobserved was 3,12 with the degree of freedom $(\mathrm{df})=60$ at the level of significance $\mathrm{p}(0,05)=2,000$. It means that tobserved is higher than ttable $(3,12>2,000)$. The result of this study shows that Semantic Mapping Strategy is significant effect on students' speaking achievement.
\end{abstract}

Keywords: Experimental Research, Semantic Mapping Strategy, Speaking Achievement

\section{A. Background of the Study}

Nowadays, Kurikulum 2013 has already been launch by our government, even though Kurikulum 2013 is still using for the grade I of Junior High School. In grade II of Junior High School is still using the curriculum that progresses now that it is called A Kurikulum Tingkat 
Satuan Pendidikan (KTSP). In this curriculum, the aim of the English teaching in Indonesia especially teaching English to Junior High School is to enable students to have the ability in developing communicative competence in both oral and written, to have the awareness about the essence and the important of English in increasing competition in global community, and the last is to develop the students' comprehension about interrelatedness between language and culture. It can be concluded that Junior High School students are demanded to master the communicative competence both in spoken and written form in order to compete in the globalization era.

In accordance with Indonesian curriculum for grade II Junior High School, the Minimum Standard Competence (KKM) is 75. The standard competence in speaking students are expected to express meaning in transactional and interpersonal short conversations to interact with their surroundings as asked, give, refuse services, giving, polite rejection, admit, deny the facts, and ask for and give opinions.

Based on my teaching experience in SMP Budi Murni 3, there are still many students who haven't able to speak English well. In addition to the data that I got, I also interviewed the teacher to ask their methods and difficulties in teaching. There are some factors found in this problem can be predicted as follows:

First, the teacher found that their methods were used by them still valued passive interaction from students. The speaking practice was done just by giving instruction so that the students were less interest.

Second, the students just memorized the conversation given by teacher to show their speaking ability. It cannot help the students to have a communicative dialogue.

These all reasons make the students just sitting and following passively in teaching learning process. There are 31 students in Grade 
VIII-A and 15 students could not pass the minimum standard competence (KKM) which is applied by school for English lesson. The score of minimum standard competence is 75 .

Many strategies can be applied to encourage the students to be actively participating in teaching learning process. The writer considers Semantic Mapping Strategy for the discussion above. This strategy provides students with a visual picture of how words or phrases connect to a concept or a topic. The teacher lists the target topic or concept and builds a web-like structure (by circling and connecting the words) of words, phrases and verbs that students offer as being connected with the central topic.

Semantic mapping is an adaptation of concept definition mapping but builds on students' prior knowledge or schema. Stone (2007: 166) adds semantic mapping is powerful tool in concept development and information ex-change. According Richards (2001: 198) semantic mapping belongs to cooperative learning and it has several characteristic, such as different topic for each group, research the information, presentation in front of the class, and structured group work effectively.

These concepts of semantic mapping will be used by writer, where students write simultaneously on piece of chart paper, drawing main concepts, supporting elements, and bridges representing in the relation of ideas in a concept because all students will have performance in front of the class.

\section{B. Research Question}

"Is there any significant effect of applying Semantic Mapping Strategy on students' speaking achievement?"

\section{The Objective of the Study}


In the relation to the problem of study, the objective of the study is to find out the effect of Semantic Mapping Strategy on Students' Speaking Achievement.

\section{The Significance of the Study}

The findings are expected to be useful theoretically and practically. Theoretically, the findings of the study may give information that semantic mapping has important role for the successful of learning process. Practically, semantic mapping strategy can be applied by teacher in teaching process. The research finding semantic mapping strategy can help students to improve their achievement on speaking.

\section{Students' Achievement in Speaking}

Achievement is defined in terms of the observable behaviors that are of interest in particular learning context (Fulcher, 2013: 18). Achievement is a result of what an individual has learned from some educational experiences. It may conclude that students' achievement is the result, the successfulness, the ability, or the standard in his or her educational learning especially by efforts, skills, and courage. Therefore, the evaluation of students' achievement is necessary. Teaching must give scores to the students' work in order to know success in teaching and the students' achievement in learning. The goal of evaluation is not only to know the students achievement but also the development and the progress of students.

Good speaking ability should engage the students by making them want to take a part. It means that the student should be active. One way of doing this is to maximize the range of language they will use. In this case, it is necessary to use acceptable form of correct language involves grammar, vocabulary, pronunciation, and fluency (Hornby: 1974). Fulcher 
argued that speaking is a complex matter. Anyone who wishes to speak second language must learn the grammar and vocabulary of the language, and master its sound. In producing the correct forms of language, the students need to practice the language they are learning.

The teacher should make some corrections and feedback to take the students' progress. Beside, the use of good and suitable strategies are truly encouraged the students to improve their speaking skill. Having good speaking, Greene (1963: 91), there are some necessary qualities to be considered, they are abilities of: 1) Thinking early, 2) Using English effectively, 3) speaking to the point, 4) discovering common interest, originally, good memory, broad minuends, adaptability, and incent. It means that in doing speaking, it is very important to have some abilities to make a good quality of speaking.

Based on the definitions above, this study is concluded that the speaking achievement is a successful of students in expressing their understanding about the materials orally to the listener. A teacher can observe the students' achievement based on the observations of a performance that the students make in the classroom. It means that the students' speaking achievement is about the accomplishing goals of teaching and learning of speaking that can observed by seeing the students' performance in using English.

\section{Speaking}

\section{a. Teaching Speaking}

Speaking is the verbal use of language to communicate with others. Speaking is the uniquely human act or process of sharing and exchanging information, ideas, and emotions using oral language, says Fisher and Frey (2007:16). However, nowadays the goal of speaking is to achieve an interactive communication between the speaker and the listener. 
Although for many years, teaching speaking has been undervalued and English teacher has continued to teach speaking just as a repetition of memorization of dialogue.

According to Brown (2004: 141-142), there are five basic types of speaking. Those five categories are as follows:

1. Imitative

This category includes the ability to practice an intonation and focusing on some particular elements of language form. That is just imitating a word, phrase or sentence. The important thing here is focusing on pronunciation. The teacher uses drilling in the teaching learning process. The reason is by using drilling, students get opportunity to listen and to orally repeat some words.

2. Intensive

This is the students' speaking performance that is practicing some phonological and grammatical aspects of language. It usually places students doing the task in pairs (group work), for example, reading aloud that includes reading paragraph, reading dialogue with partner in turn, reading information from chart, etc.

3. Responsive

Responsive performance includes interaction and test comprehension but at the somewhat limited level of very short conversation, standard greeting and small talk, simple request and comments. This is a kind of short replies to teacher or studentinitiated questions or comments, giving instructions and directions. Those replies are usually sufficient and meaningful.

4. Interactive

- Transactional (dialogue) 
It is carried out for the purpose of conveying or exchanging specific information. For example here is conversation which is done in pair work.

- Interpersonal (dialogue)

It is carried out more for the purpose of maintaining social relationships than for the transmission of facts and information. The forms of interpersonal speaking performance are interview, role play, discussions, conversations and games.

5. Extensive (monologue)

Teacher gives students extended monologues in the form of oral reports, summaries, and storytelling and short speeches.

It concluded that speaking in a classroom involves the interaction between teachers and students or among the students which depends on how classroom activities are organized. It means teaching and learning in classroom need the good and suitable strategies to reach the goal of speaking.

\section{b. The Assessment of Speaking}

To know students' speaking ability there are some possible assessment according to Keith (2006: 214-219). Teacher can focus on a variety of these three areas of speaking assessment, including pronunciation, fluency, and language accuracy.

1. Pronunciation

Good pronunciation certainly contributes to good speaking. In pronunciation the speaker has a marked accent that inhibits communication, the learner can pronounce a range of sounds in English, and there are certain sounds that the learner cannot say. One way to assess learners' ability to pronounce certain sounds is to devise a short paragraph or a series of sentences that include sounds that teacher want to 
assess. One of the advantages in this assessment is that you can make sure that every sound teacher taught and practiced is assessed.

2. Fluency

The fluent describe a certain speaker. Fluency means that the speaker's English is correct more often than not it refers to the ability of the speaker to deliver a communication or message at a normal speed. Thus, fluency refers to the amount of language delivered, not necessarily accuracy. In good fluency, the speaker stops frequently to search for words, the speaker uses words that accurately reflect his or her actual social level, the speaker conveys an intended message without an unnatural amount of hesitation or self-corrections or self interruptions. One advantage of this system is that it is relatively easy to obtain student data and easy for student to follow.

\section{Language Accuracy}

Everyone agrees that the accuracy of learner language is important, but we have seen that obsessing over accuracy does not necessarily produce a cadre of accurate second language speaker. One way to assess accuracy of spoken language is to count errors. The advantage of this assessment as an accuracy assessment is that it is natural language and it is relatively easy to score.

\section{Semantic Mapping Strategy}

a. Semantic Mapping as One Type of Graphic Organizers

Heimlich \& Pittelman (1986: 44) explained that a semantic map is one type of graphic organizer. It helps students visually organize and graphically show the relationship between one piece of information and another. This strategy has been identified by researchers as an excellent technique for increasing vocabulary and improving speaking achievement. 
Fisher (1995) states that semantic mapping allows the learner to create an understanding of the world by making connections, by creating links, by exploring and testing links (a basic process of all creative thinking). It has been used to help students and teachers to build an organized knowledge base in a given discipline, states Pankratius (1990) or a given topic (Kopec, Wood \& Brody, 1990). They help students learn new information, and they even tie the existing knowledge students possess to new information that they are learning, adds Dexter and Hughes (2011: 52).

Boon Yih (2011) found that Semantic Mapping leads students to discuss their idea in group, make students can explore their creativity in giving their ideas critically, so it is useful in teaching essay writing and vocabulary.

\section{b. The Reasons of Using Semantic Map as One Type of Graphic Organizers}

There are three compelling reasons why you should use graphic organizers (Edwin: 2004), as follows:

1. Students are considerably more likely to understand and remember the content subject you are teaching. Simply put, the information tends to be less "fuzzy" and more precise. Graphics help students separate what is important to know from what might be interesting, but not essential information.

2. Because the semantic information processing demands are reduced, you can often address the content at more sophisticated or complex levels; this is especially true for many students with learning disabilities. Showing (as opposed to just telling) how the information is structured can be a powerful way to facilitate understanding. 
3. Students are more likely to become strategic learners. Reading and writing skills, communication skills, and analytical, critical, and creative thinking skills are all subject to improve when students learn recognize these patterns of thinking, construct, and use graphic organizers.

Based on three advantages of using graphic organizers in learning process, it makes students are better able to learn and internalize information when more than one learning modality is employed in an instructional strategy. Since graphic organizers present material through the visual and spatial modalities, the use of graphic organizers helps students internalize what they are learning.

\section{c. The Advantages of Semantic Mapping Strategy}

According to Fisher (1995) there are some advantages of semantic mapping strategy, they are:

1. It clearly defines the central idea, by positioning it in the center of the page.

2. It allows the students to indicate clearly the relative importance of each idea.

3. It allows the students to figure out the links the key ideas more easily. This is particularly important for creative work such as easy writing.

4. It allows the students to see all their basic information on one page.

5. It allows the students to add in new information without messy scratching out or sequencing it.

6. It makes easier for the students to see the information in different way, from different viewpoints because it does not lock it into specific position. 
Figure 1. The Steps and Concept of Applying Mind Mapping in the Class

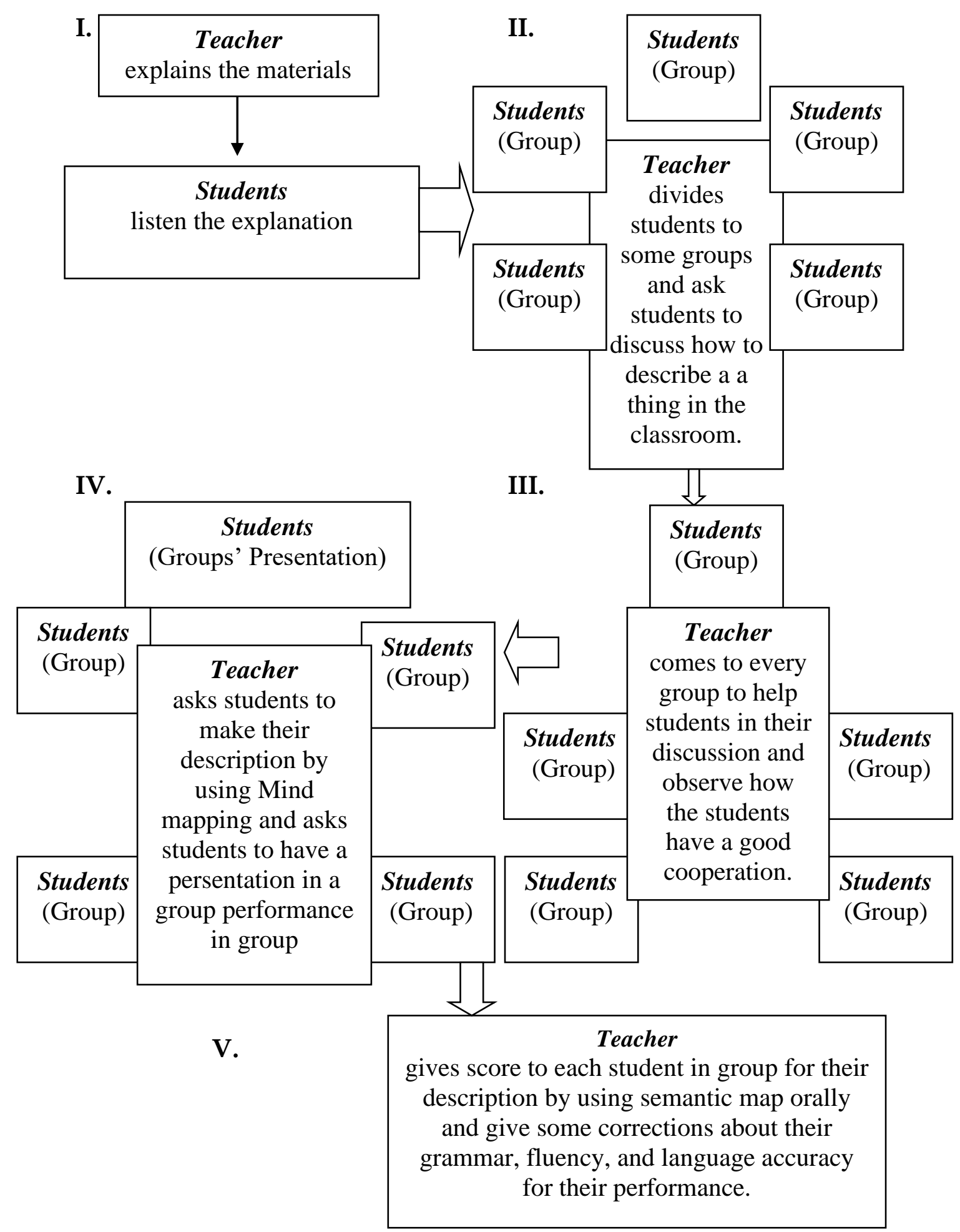




\section{Previous Studies}

Based on Yagoub Zahedi and Mortaza Abdi on the title "The Effect of Semantic Mapping Strategy on EFL Learners' Vocabulary Learning", vocabulary is the basic access to language; however, language beginners may not be good at applying methods to help them memorize words. The main objective of this study was to compare the effect of semantic mapping strategy on forty Iranian EGP learners' vocabulary mastery. The participants were randomly assigned to a control group that received traditional direct translation and the treatment group that received instruction on semantic mapping. In order to assess the efficiency of the strategy, a pre-test and post-test was administrated to both groups. The results show that using semantic mapping strategy resulted in a significant difference in the participants' vocabulary learning.

Based on Elmira Taghavi and Karim Sadeghi on the title "The Effect of Semantic Mapping on Reading Comprehension", the research examined the relative effectiveness of semantic mapping, as an interactive pre-reading strategy, on reading comprehension of Iranian undergraduate students (non-EFL majors). It also examined whether there was an interaction between gender and the effect of teaching semantic mapping strategy on reading comprehension. The participants in this study consisted of 120 male and female pre-intermediate undergraduate students taking a General English course at UrmiaUniversity in Spring 2008. A Certificate of Advanced English Reading Paper (CAE) was administered to measure the students' proficiency at the beginning of the research. Later, the participants were semi-randomly (Mackey and Gass, 2005) assigned into experimental and control groups. The experimental group was instructed on how toemploy semantic mapping strategy in reading while the control group received normal reading instruction. The post-test results 
supported the findings of earlier research that instruction on the application of semantic mapping contributed to reading comprehension.

\section{Finding/Discussion}

The Calculation of the $t$-table and $t$-observed

\section{The Calculation of the t-table}

\begin{tabular}{|c|c|c|c|}
\hline \multicolumn{4}{|c|}{$=(31+31)-2$} \\
\hline \multicolumn{4}{|c|}{$=62-2$} \\
\hline \multicolumn{4}{|c|}{ With $(a=0.05)$} \\
\hline df & 0.10 & 0.05 & 0.02 \\
\hline 60 & 1.671 & 2.000 & 2.390 \\
\hline 65 & 1.669 & 1.997 & 2.385 \\
\hline 70 & 1.667 & 1.994 & 2.381 \\
\hline
\end{tabular}

From the precentage points of the T-Distribution with "two tail Probabilities, we can conclude that "T-Table $=2.000$ "

\section{The Calculationg of the t-observed}

$$
\begin{aligned}
& \text { Ascertainable: } \mathrm{Mx}=19.32 \quad \text { My }=14.29 \\
& \sum \mathrm{dx}^{2}=1150.54 \sum \mathrm{dy}^{2}=1232.26 \\
& \mathrm{Nx}=31 \mathrm{Ny}=31 \\
& \mathrm{t}=\frac{M_{x-M_{y}}}{\sqrt{\left(\frac{\sum d X^{2}+\sum d Y^{2}}{\left.N_{X+N_{Y}-2}\right)}\left(\frac{1}{N_{X}}+\frac{1}{N_{Y}}\right)\right.}} \\
& \mathrm{t}=\frac{19.32-14.29}{\sqrt{\left(\frac{1150.54+1232.26}{31+31-2}\right)}\left(\frac{1}{31}+\frac{1}{31}\right)}
\end{aligned}
$$




$$
\begin{aligned}
& t=\frac{5.03}{\sqrt{\left(\frac{2382.8}{60}\right)\left(\frac{2}{31}\right)}} \\
& t=\frac{5.03}{\sqrt{39.71 x 0.065}} \\
& t=\frac{5.03}{\sqrt{2.58}} \\
& t=\frac{5.03}{1.61} \\
& t-\text { observed }=3.12 \\
& H a=t \text {-observed }>\text { t-table } \\
& H a=3.12>2.000
\end{aligned}
$$

According the calculation, the researcher consulted the critical value on the $\mathrm{t}$-table to check whether the difference was significant or not. Before the experiment was conducted, the level of significance to be used in the experiment had been divided first. For this experiment, the researcher used $5 \%(0,05)$ alpha level of significance as usually used in psychological and educational research.

Based on the data analysis, the two score of both experimental and control groups were different after giving different treatment. The mean score of the experimental group was higher than control group (19.32 > 14.29).

The result of the $t$-test calculation also showed that $t$-observed value (3.12) was higher than t-table value (2.000) with $a=0.05$ and $\mathrm{df}=60$, so Hypothesis Alternative is accepted. It indicates that Semantic Mapping Strategy significantly affects that students' speaking achievement.

From the result, it could be concluded that difference was statistically significant. Therefore, based on the computation there was significant 
difference between teaching speaking descriptive text using and without Semantic Mapping Strategy.

Teaching speaking descriptive text using Semantic Mapping Strategy was more effective than teaching speaking descriptive text without using Semantic Mapping Strategy. It could be seen by the result of the test where the students' score was higher after giving the treatment.

Both the test, pre-test and post-test was aimed at measuring the students' achievement in learning speaking by using Semantic Mapping Strategy. The pos-test was given after explained the semantic mapping strategy. The researcher can distinguish and compare the result of the test. By calculating the result of the test, it can be distinguish between the pretest and post-test which showed that the using of semantic mapping can improve the students' achievement in speaking descriptive text.

Based on the research which the researcher has done, the researcher found out that there are some advantages of using Semantic Mapping Strategy in teaching speaking, they are:

a. The students have a high interest in following teaching learning process. Most of the students more interest with something new especially in teaching learning process. The use of semantic mapping in speaking class can be learned to an interesting circumstances. So it will not too difficult for teacher to transfer the material to the students.

b. Between teacher and students more interactive because in drafting the map, the students are active participant throughout the development of the map.

c. Using semantic mapping, the mind of students more focus because they are only to look for some words or characteristic from the topic. 
d. The students are trained to think fast automatically; for example, when the teacher writes the topic on the whiteboard, the teacher will provide so limited time, since they will observe the topic, and then they have to give response in few second. It will be accustomed to think fast.

e. It is easy to memorize, remember, and can avoid misunderstanding because the students see the map directly before write the topic become a text and before having performing in front of the class.

\section{Conclusion}

The Semantic Mapping Strategy in teaching speaking descriptive text was effective when applied in the eighth grade of SMPN Budi Murni 3. Based on the result of research, there was a significance difference in the achievement between students in class VIII-1 who were taught descriptive text through Semantic Mapping Strategy and students in class VIII-3 who were taught descriptive text without using Semantic Mapping Strategy. The mean score of the experimental group was higher than control group $(19.32>14.29)$. It was also proved by the result of $t$-test. The result of the $t-$ test calculation also showed that t-observed value (3.12) was higher than $\mathrm{t}$ table value (2.000) with $\mathrm{a}=0.05$ and $\mathrm{df}=60$. It means that $\mathrm{Ha}$ was accepted and Ho was rejected.

In conclusion, Semantic Mapping Strategy was very effective to teach descriptive text at the the eighth grade of SMP Budi Murni 3. In additon, Semantic Mapping gave significant effect on students' speaking achievement.

In the relation to the conclusion above, the writer points out some suggestions as follow: 
1) Semantic Mapping should be applied in the teaching process because it could be as guidance to facilitate the students by using a map for having performance in speaking in the classroom.

2) Students or English learners should be brave and always want to practice in speaking English because this strategy can help students to improve their achievement in speaking

3) Other researchers who intend to use Semantic Mapping Strategy in teaching learning process; he or she is hoped to do the research by using another strategy and try to find another effective media, so it will enrich the research in improving students' speaking achievement.

\section{References}

Amoush, Kholoud Hussei. The Effectiveness of Using "Semantic Mapping strategy" on Reading Comprehension of Jordanian University Students. ijcrb.webs.com, Vol 4, No. 6, October 2012

Boon Yih, Mah. 2011. Semantic Mapping: A Visual and Structured Prewriting Strategy in the Process of Essay Writing. ESTEEM Academic Journal UiTM Pulau Pinang, 7, 81-92.

Brown, H Dowglas. 2004. Language Assessment: Principles and Classroom Practices, Chapter 7. San Francisco: Pearson Longman.

Ellis, Edwin. 2004. Q\&A: What's the Big Deal with Graphic Organizer. www.GraphicOrganizers.com, (251) 961-2407

Folse, Keith S. 2006. The Art of Teaching Speaking: Research and Pedagogy for the ESL/EFL Classroom. USA: The University of Michigan

Fulcher, G. 2003. Testing Second Language Speaking. Great Britain: Pearson Education Limited.

Hughes, Rebecca. 2002. Teaching and Researching Speaking. Great Britain: Longman 
JADEs: Journal of Academia in English Education

Nation, I.S.P and Newton, J. 2009. Teaching ESL / EFL Listening and Speaking. United Kingdom: Routledge Taylor and Francis Group

Ngoc Thuy, Nguyen. 2003. The Effects of Semantic Mapping on Vocabulary Memorizing. Viet Nam: www.asia-efl-journal.com

Richards, Jack C and Renandya, Willy A. 2002. Methodology in Language Teaching. London: Cambridge University Press

Setiyadi. 2006. Teaching English as a Foreign Language. Yogyakarta: Graha Ilmu

Stone, Jeanne M. 2007. Cooperative Learning Reading Activities. Australia: Hawker Brownlow Education.

Taigin, D. 1995. A Strategy for Effective Inter Class Oral Communication. Forum, 28.

Urawan, Agus. 2013. Using Semantic Mapping Strategy to Improve Students' Achievement in Writing Descriptive Text. Semarang: IKIP PGRI Semarang 